OPEN ACCESS

Edited by:

Weiwei Xue,

Chongqing University, China

Reviewed by:

Zhiwei Feng,

University of Pittsburgh, United States

Shiliang $\mathrm{Li}$,

East China University of Science and

Technology, China

*Correspondence:

Shuguang Yuan

shuguang.yuan@siat.ac.cn

Specialty section: This article was submitted to Pharmacology of Anti-Cancer Drugs, a section of the journal Frontiers in Pharmacology

Received: 12 March 2020 Accepted: 01 May 2020 Published: 20 May 2020

Citation: Cui W, Aouidate A, Wang S, Yu Q, Li Y and Yuan S (2020) Discovering Anti-Cancer Drugs via Computational Methods.

Front. Pharmacol. 11:733. doi: 10.3389/fphar.2020.00733

\section{Discovering Anti-Cancer Drugs via Computational Methods}

\author{
Wenqiang Cui ${ }^{1,2}$, Adnane Aouidate ${ }^{1}$, Shouguo Wang $^{1}$, Qiuliyang $\mathrm{Yu}^{1}{ }^{1}$, Yanhua $\mathrm{Li}^{2}$ \\ and Shuguang Yuan ${ }^{1 *}$ \\ 1 Shenzhen Institutes of Advanced Technology, Chinese Academy of Sciences, Shenzhen, China, ${ }^{2}$ College of Veterinary \\ Medicine, Northeast Agricultural University, Harbin, China
}

New drug discovery has been acknowledged as a complicated, expensive, timeconsuming, and challenging project. It has been estimated that around 12 years and 2.7 billion USD, on average, are demanded for a new drug discovery via traditional drug development pipeline. How to reduce the research cost and speed up the development process of new drug discovery has become a challenging, urgent question for the pharmaceutical industry. Computer-aided drug discovery (CADD) has emerged as a powerful, and promising technology for faster, cheaper, and more effective drug design. Recently, the rapid growth of computational tools for drug discovery, including anticancer therapies, has exhibited a significant and outstanding impact on anticancer drug design, and has also provided fruitful insights into the area of cancer therapy. In this work, we discussed the different subareas of the computer-aided drug discovery process with a focus on anticancer drugs.

Keywords: anti-cancer, CADD, drug discovery, Al, computational methods

\section{INTRODUCTION}

Up to now, cancer remains a global and serious public health challenge. It is estimated that there are more than 200 different types of cancer, generally named according to the tissue where the cancer was recognized for the first time. Cancer is considered to be one of the significant causes for death in the 21 st century and the most critical obstacle for the increase of global life expectancy. According to an analysis by the world health organization (WHO) in 2015, cancer is the second leading cause of death for patients younger than 70 years old in 91 countries and the third or fourth leading cause of death among 22 other countries (Yan et al., 2019). Moreover, a global increase of 18.1 million new cancer cases and 9.6 million cancer-related deaths have been reported in a previous study (Bray et al., 2018), especially 70\% of the death caused by cancer occur in low-income and middle-income countries. The fast growth of the cancer incidence and mortality has turned out to be global health challenges. How to reduce the cancer-related death rate has attracted significant attention from the government, society, medical industry, as well as scientific communities, expecting the rapid development of effective and safe drugs for cancer treatment.

Despite of the impressive progress in biotechnologies and further understandings of the disease biology, the development of new, practical and innovative small molecule drugs remains an arduous, time-consuming, and expensive project, which requires collaborations from many expertise in multidisciplinary fields, including medicinal chemistry, computational chemistry, biology, drug metabolism, clinical research, etc. Furthermore, it has been illustrated that the 
successful discovery and development of a new drug costs 12 years, and expensive investment (Kapetanovic, 2008). Thus, novel drug development strategies with a reduced cost of time and money, as well as an enhanced efficiency are in high demand, which would contribute to a significant improvement in global health and life expectancy. Since the successful development of HIV protease inhibitor Viracept in the USA in 1997, which was the first drug design fully driven by its target structure (Kaldor et al., 1997), computational methods have served as an essential tool in drug discovery projects and have been a cornerstone for new drug development approaches. This makes the drug developmental process faster and cheaper. Recently, the fast growth in computational power, including massively parallel computing on graphical processing units (GPUs), the continuous advances in artificial intelligence (AI) tools (Chan et al., 2019; Yang et al., 2019), have translated fundamental research into practical applications (Zhavoronkov et al., 2019) in the drug discovery field. This attracted considerable attention for their outstanding performance on providing new promising perspectives and solutions to overcome life-threatening diseases.

In this review, we aim at providing an overview of different subjects of the computational-method-aided new drug discovery processes in general, and anti-cancer therapy discovery in particular. We reviewed some of the most representative examples and clarified fundamental principles by exploring studies on anticancer drug designs with the help of computational methods. A workflow of computational drug discovery is explained in Figure 1.

\section{ANTI-CANCER DRUG TARGET PREDICTION}

Human contains approximately 30,000 genes, among which around 6,000 to 8,000 sites are estimated as potential pharmacological targets. However, less than 400 encoded proteins have been proved to be effective for drug development until now (Drews, 2000; Chen et al., 2016). Cancer, compared to many other human diseases, now has a plethora of potential molecular targets for therapeutic development (Lazo and Sharlow, 2016). Traditional drug discovery mainly follows the paradigm of "one molecule - one target - one disease", without considering the interactions between drugs and proteins. However, an important fact that many complex diseases are relevant to a variety of target proteins (Hopkins, 2008; Yamanishi et al., 2008; Chen et al., 2012) has been overlooked. Furthermore, unexpected drug functions derived from off-targets are an accidental and uncontrollable activities because of the "poly-pharmacological" properties of certain drugs, which might result in undesirable side effects. Those are particularly pronounced for cancer drugs. On the other hand, there are some positive examples that benefit from the different pathways targeted by one given molecule. For example, sildenafil (viagra)

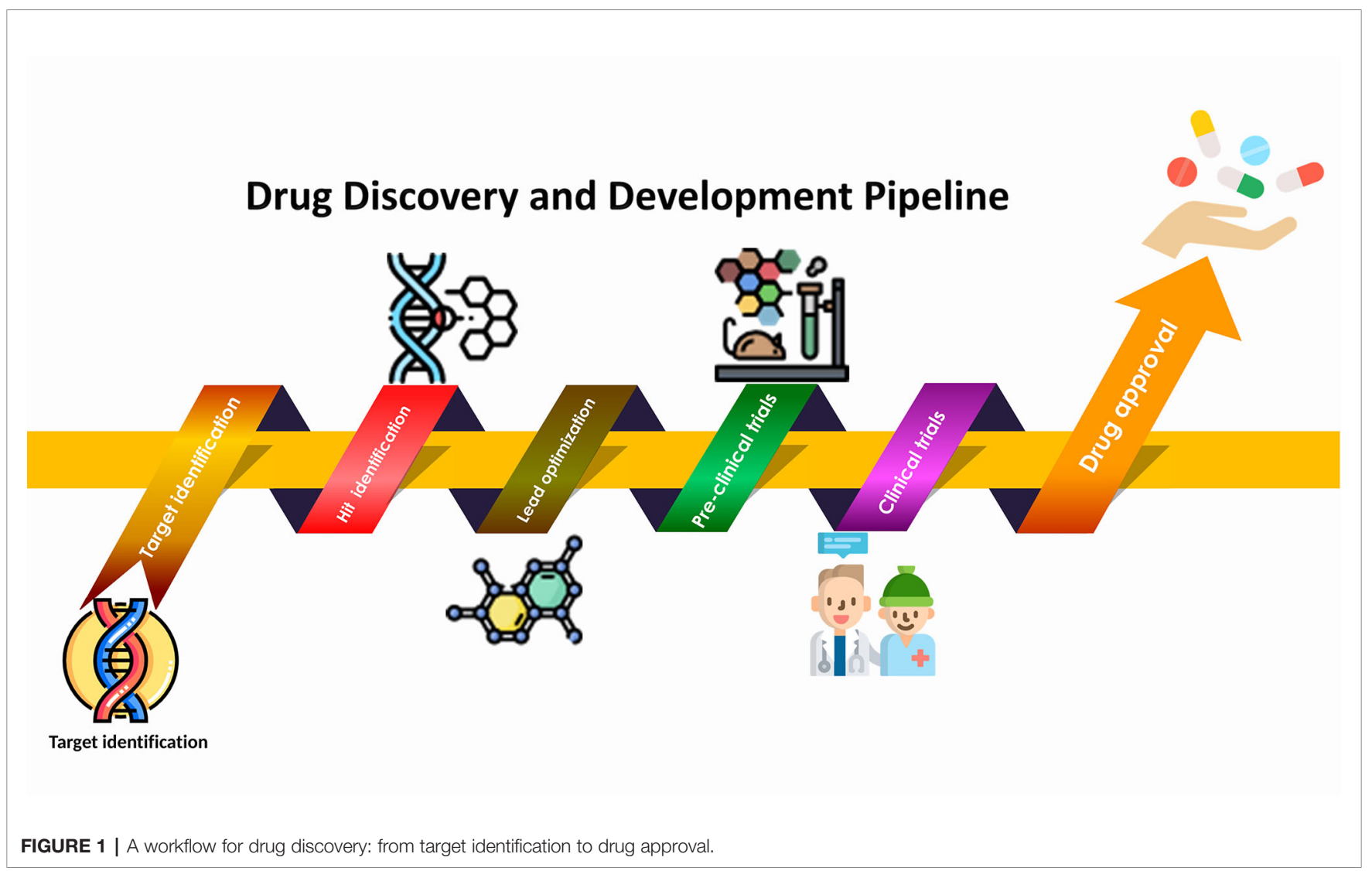


was developed to treat angina, but now it is used for erectile dysfunction therapy (Ghofrani et al., 2006). There are several drugs, including anticancer drugs, whose corresponding target proteins (both primary and non-target) remain yet unidentified or unknown (Takarabe et al., 2012). Furthermore, some attractive and potentially effective cancer targets remain outside of the scope of pharmacological regulation. Some of these targets such as phosphatases, transcription factors, and RAS family members have been described as undruggable, as they lack effective enzymatic active sites (Lazo and Sharlow, 2016). To make the full use of known drugs to treat new indications, the characterization of all potential new ligand binding sites has been illustrated as a key point in drug repositioning and repurposing. Therefore, new and highly qualitative bioinformatic target prediction methods are required for the accurate prediction of drug targets.

Up to now, a wide range of drug target interactive web servers has been established, providing a series of drug-target databases and prediction tools (see Tables 1 and 2). Moreover, various computational approaches have been used to study potential interactions between proteins and drugs. In particular, network-based models and ML-based models have emerged as important tools. A review by Chen et al. summarizes several available computational models for this application (Chen et al., 2016). Interestingly, a method proposed by Campillos et al. that uses the similarity of drug side effects to determine whether multiple drugs could interact with the same target proteins attracted our attention (Campillos et al., 2008). Based on this research,

TABLE 1 | Drug-target database.

\begin{tabular}{ll}
\hline Databases & \multicolumn{1}{c}{ Websites } \\
\hline DrugBank & https://www.drugbank.ca/ \\
TTD & http://bidd.nus.edu.sg/group/ttd/ttd.asp \\
MATADOR & http://matador.embl.de/ \\
SuperTarget & http://insilico.charite.de/supertarget/ \\
TDR targets & http://tdrtargets.org/ \\
PDTD & http://www.dddc.ac.cn/pdtd/ \\
ChEMBL & https://www.ebi.ac.uk/chembldb \\
STITCH & http://stitch.embl.de/ \\
BindingDB & http://www.bindingdb.org/ \\
CancerDR & http://crdd.osdd.net/raghava/cancerdr/ \\
DCDB & http://www.cls.zju.edu.cn/dcdb/
\end{tabular}

TABLE 2 | Computational tools for target prediction.

\begin{tabular}{ll}
\hline Computational tools & \multicolumn{1}{c}{ Websites } \\
\hline SEA & https://omictools.com/sea-2-tool \\
Pharmmapper & http://www.lilab-ecust.cn/pharmmapper/ \\
Chemmapper & https://omictools.com/chemmapper-tool \\
Tide & http://sysbio.molgen.mpg.de/tide \\
DINIES & http://www.genome.jp/tools/dinies/ \\
SuperPred & http://prediction.charite.de/ \\
SwissTarget Prediction & http://www.swisstargetprediction.ch/
\end{tabular}

Takarabe et al. took advantage of the US FDA's adverse event reporting system (AERS) to define the pharmacological similarity of all potential medicines and developed a novel system to predict large-scale interactions between unknown drug-targets (Takarabe et al., 2012). Notably, AERS was employed to predict interactions between drugs and targets for the first time. In 2010, Klipp et al. summarized several available computational models for network-based drugtarget prediction (Klipp et al., 2010). Moreover, various biological data settings, including structures of bioactive compounds, sequences of target proteins, and information of ligand-target interactions, have been combined. A series of machine learning-based approaches have been demonstrated as efficient tools in detecting relationships among drug structures and corresponding target proteins from a large amount of data, such as supervised learning method (Srivastava et al., 2014), bipartite graph learning method (Li and Chen, 2013), bipartite local model (Yildirim et al., 2007), and so on. A recent review by Mayr et al. compared the predictive performance of deep learning with other prediction approaches for multiple drug targets in the comparative studies of composite target prediction methods. As a result, feed-forward neural networks were identified with better performance in drug target prediction than other methods (Mayr et al., 2018).

As above, since a large number of compounds and vigorous efforts are abandoned and wasted due to the off-target effects during the classical drug development procedure, a greatly enhanced development of target prediction in new drug exploration exhibited attractive advantages and further expansion in this area are still highly desirable

\section{STRUCTURE-BASED DRUG DISCOVERY}

Structure-based strategy relies on the known structural information to define the interaction effect between bioactive compounds and the corresponding receptors. (Wang et al., 2000). With the development of biomolecular spectroscopic technologies such as X-ray crystallography and nuclear magnetic resonance (NMR), remarkable progress has been made in this field, leading to considerable improvements in our structural understanding of the drug target. Taking advantages of the three-dimensional structure of the proteins, new ligands could be rationally designed to trigger therapeutic effects. Hence, structure-based design (SBD) could provide critical insights into new drug design and development via discovering and optimizing the initial lead compounds (PradaGracia et al., 2016; Lu et al., 2018a). The high affinity ligand regulates validated drug targets selectively to influence specific cellular activities, ultimately achieving the desired pharmacological, and therapeutic effects (Urwyler, 2011). Capoten (captopril), the first ACE (angiotensin-converting enzyme) inhibitor, was one of the first successful examples of using structural information to optimize drug designs in the 1980s (Anthony et al., 2012). Since this study, structure-based 
drug development started to serve as a novel and powerful algorithm and technique to promote faster, cheaper, and more effective drug development. In the past decade, extensive efforts have been made to promote the strategy of SBD, more and more successful applications played important roles in new medical research (Debnath et al., 2019; Hong et al., 2019; Mendoza et al., 2019; Itoh, 2020; Tondo et al., 2020).

\section{Molecular Docking}

Molecular docking is a typical structure-based protocol in rational drug design by studying and predicting the binding patterns and interaction affinities among the ligand and receptor biomolecules (Ferreira et al., 2015). It could be categorized as rigid docking and flexible docking according to the flexibility of the ligands involved in the computational process (Halperin et al., 2002; Dias and De Azevedo, 2008). The rigid docking method is a binding model which only considers the static geometrical, physical, and chemical complementarity between the ligand and the target proteins, while ignores the flexibility and the induced-fit theory (Salmaso and Moro, 2018). In general, the rigid docking, which is fast and highly effective, is applied to the high throughput virtual screening with a large number of small-molecule databases to be time-efficient. While the flexible docking method considers more detailed and accurate information. With the rapid improvement of computing resources and efficiency, flexible docking methods developed continuously and became more easily accessible. There are different types of software available for docking, such as Glide, FlexX, DOCK, AutoDock, Discovery Studio, Sybyl, etc.

The molecular docking process is mainly composed of three steps. First, the structures of small molecules and target proteins should be prepared in advance. In this step, abundant experimentally solved structures are available in the open access PDB database (http://www.rcsb.org), which can be used to understand many physiological processes based on the crystal structures, and also for homologous template models if docking structures are of interest. Second, it can act as an engine for predicting conformations, orientations, and positional spaces in the ligand binding site (Mathi et al., 2018). Conformational search algorithms carry out this task to predict the conformations of binary complexes by applying the methods of systematic and stochastic search. Systematic search techniques include: (i) Exhaustive search; (ii) Fragmentation; (iii) Conformational Ensemble. On the other hand, stochastic methods include: (i) Monte Carlo (MC) methods; (ii) Tabu search methods; (iii) Evolutionary Algorithms (EA); (IV) Swarm optimization (SO) methods (Ferreira et al., 2015). Finally, these programs evaluate the putative binding-free energy, which associates the scoring function to determine which compounds are more likely to bind to targets during the molecular docking (Huang et al., 2010). There are four essential types of scoring functions, including: (i) Consensus scoring functions (ii) Empirical scoring functions; (iii) Knowledge-based scoring functions; (iv) Force-field based scoring functions (Kortagere and Ekins, 2010). Furthermore, new scoring capabilities have been developed, for example (i) machine learning technologies; (ii) interactive fingerprints; (iii) quantum mechanical scores (Yuriev et al., 2015).

\section{Structure-Based Pharmacophore Mapping}

With the development in the past decades, the pharmacophore mapping method has been considered as one of the most useful technology during the process of drug discovery. All kinds of structure-based approaches have been conducted to improve pharmacophore modeling, which has been widely used for virtual screening, de novo design as well as lead optimization (Yang, 2010; Lu et al., 2018a). The structure-based pharmacophore $(\mathrm{SBP})$ is another useful method. Based on the availability of ligand structures, SBP modeling methods can be cataloged into two types: target-ligand complex-based methods and target-binding site-based (without ligand) methods (Pirhadi et al., 2013). The approach based on the target-ligand complex can conveniently locate the ligand-binding pocket of the protein and assess the main ligand-protein interactions. This is exampled by LigandScout (Wolber et al., 2006), Pocket v.2 (Chen and Lai, 2006), and GBPM (Ortuso et al., 2006). It is worth noting that they cannot be used to the situations where ligands are unknown. The macromolecule (without ligand)-based method implemented in Discovery Studio (Lu et al., 2018b) is an obvious example which is not dependent on the ligands and the receptor-ligand interactions. The LUDI program (Bohm, 1992) defines the interactions within the binding site as pharmacological characteristics. Although this purely SBP method has the advantage of describing the entire interaction capability of a binding pocket, the main limitation of this method is that the derived interaction maps typically involve many unprioritized interaction features.

\section{LIGAND-BASED DRUG DISCOVERY}

\section{Similarity Searching}

The main principle and motivation behind the ligand-based approaches in drug discovery is a concept known as molecular similarity; based on this principle, molecules tend to perform similar biological effects due to the high structural similarity (Zhavoronkov et al., 2019). In other words, ligand-based drug discovery methods rely on the structural information of the active ligand that interacts with the target protein, and such a compound with interesting biological properties can be used as a query template in identifying and predicting new chemical entities with similar properties. Since only the structure of the known active small molecules are required, this methodology is considered as an indirective protocol for drug discovery. It offers an option when the $3 \mathrm{D}$ target protein structure is unknown or cannot be predicted. Hence, this approach is commonly applied to screen novel ligands with interesting biological activities in silico and to optimize the biological activities of ligands to improve drug pharmacokinetics including Adsorption, Distribution, Metabolism, Excretion, Toxicity (ADMET) properties.

This simple and most widely used technique is based on molecular descriptors. Physicochemical properties (e.g., molecular weight, $\log$, Energy of high occupied molecular orbital (EHOMO), Energy of lowest unoccupied orbital (ELUMO), charges), as well as 2D fingerprint and 3D shapesimilarity searches can be introduced as coordinates to represent 
the reference compounds. The 2D fingerprint (Molprint2D and Unity 2D) and 3D shape similarity methods (MACCS), extended-connectivity fingerprints (ECFP), rapid overlay of chemical structures (ROCS), and Phase Shape, are more often used for molecular representation in virtual screening (Rush et al., 2005). For example, Bologa et al. (2006) applied 2D fingerprint and 3D shape-similarity methods to identify novel agonists of the estradiol receptor family receptor GPR30 (Bologa et al.). Furthermore, both methods have been successfully applied in virtual screenings, and both technology have exhibited better performance against a number of targets than docking methods in terms of the scalability and computational time. However, the main problem of the similar methods is their preference for input molecules and the difficulty in deciding which input structures to be used (Hu et al., 2012).

\section{Ligand-Based Pharmacophore Mapping}

Another more precise approach in comparison with the molecular descriptors is the pharmacophore-based approach, in which a pharmacophore model (PH4) is developed based on a group of active compounds. The IUPAC (International Union of Pure and Applied Chemistry) pointed out that a pharmacophore is "a collection of spatial and electronic characteristics necessary to ensure optimal supramolecular interactions with specific biological targets and to trigger (or block) their biological reactions" (Buckle et al., 2013). Thus, structural overlap of key molecular features derived from active compounds or a binding site in space are used as a pattern to represent the most probable chemical characteristics. The newly identified molecules that match and show a high complementation to the developed pharmacophore are likely to be active against the target protein of interests. Therefore, they can be selected as candidates for more further investigations. This approach has become a key computational strategy to promote and guide drug discoveries in the absence of macromolecular structures (Chao et al., 2007).

The process of pharmacophore modelling can be summarized as following: (i) Selection of a training set of ligands (active and inactive compounds). (ii) Molecular preparation (low energy conformations). (iii) Ligand alignment/superimposition and pharmacophore model generation. (iv) Validation of pharmacophore models (Chiang et al., 2009). Ligand-based pharmacophore modeling highly depends on the availability of a good training set of compounds manifesting the same binding mode.

\section{QSAR Modeling}

QSAR (Quantitative Structure Activity Relationship) is another ligand-based approach that relies on analyzing the biological activities of drugs using various molecular descriptors (MDs) or fingerprints (FPs). These models mathematically describe how the activities response to the targets according to the ligand's structural characteristics. QSAR was obtained by calculating the correlations between the properties of the ligand binding agent and the biological activity measured by experiments. Different ML and deep learning (DL) approaches have also been applied to develop QSAR models (Mendenhall and Meiler, 2016): including Support Vector Machine (SVM), Random Forest (RF),
Polynomial Regression (PR), Multi Linear Regression (MLR), Artificial Neural Network (ANN). Unlike the pharmacophore models, QSAR models can measure biological activities quantitatively and can even find positive or negative effects according to certain characteristics of the molecule on its activity.

QSAR has been applied to many other molecular design purposes, such as predicting the new molecule analog activity, optimizing lead, and predicting new structural leads in drug discovery. In the classical 2D-QSAR approaches, the biological activity is related to physical and chemical features consisting of steric, electronic, and hydrophobic characters of drugs, and the relationships are represented as mathematical equations (Hansch and Fujita, 1964). More advanced 3D-QSAR approaches, such as comparative molecular field analysis (Cramer et al., 1988) and molecular similarity indexes in a comparative analysis (Klebe et al., 1994), are based on the force field calculations. The structural information of molecules is needed, and developed models are represented in $3 \mathrm{D}$ contour maps facilitating the visualization and interpretation.

\section{USING MD SIMULATION TO FIND NEW DRUG BINDING SITES}

Many important biological events rely on the information of protein-ligand complex interactions. The recognition and characterization of LBP is the key to understand the function of endogenous ligands and synthetic drug molecules. GPCRs perform an important role in a variety of physiological processes. GPCRs are a class of commonly used targets in drug discovery (Conn et al., 2009). Recent discovery indicated that beside binding to orthosteric sites, ligands could bind to different allosteric sites that are far away from the targeted binding pockets (Tautermann, 2014; Flock et al., 2015; Devree et al., 2016). Unfortunately, the position of such allosteric pocket is unclear without the information of experimental structures, and predicting the existence of such sites could facilitate the discovery of new drugs (Tautermann, 2014). A recent overview described the progresses in important computational tools for the prediction of functional sites, such as 3DLigandStie (http://www.sbg.bio.ic.ac.uk/ 3dligandsite/), COACH-D (http://yanglab.nankai.edu.cn/COACH-D/), or SiteMap (https://www.schrodinger.com/sitemap), and many others. However, these reported tools often create multiple possible ligand binding sites, and sometimes it is not easy for the user to confirm which active pocket is real one for the compound binding. To overcome this limitation, methods based on molecular dynamics (MD) have been developed in recent years. For example, the supervised MD is an efficient approach for precise sampling and the identification of ligand-binding sites (Sabbadin and Moro, 2014; Deganutti et al., 2015; Cuzzolin et al., 2016). The conventional longtimescale MD has also been successfully applied for new drug binding sites (Chan et al., 2018). Similarly, a study by Chan et al. (2020) reported that an additional sodium ion, which located in the vicinity of the orthosteric binding site, by $\mathrm{MD}$ simulations (Chan et al., 2020). MD could also be applied for the recognition of the allosteric sites involved in protein kinases (Tong and Seeliger, 2015), 
Ras proteins (Hancock, 2003), and Staphylococcus aureus Sortase A (Mazmanian et al., 1999). As above, information obtained from MD predictions provides new opportunities of drug discovery.

\section{ARTIFICIAL INTELLIGENCE IN ANTI- CANCER DRUG DISCOVERY}

Computational drug design has successfully promoted the discovery of several new anticancer drugs, which has become a milestone in this area. Gefitinib (Muhsin et al., 2003), Erlotinib (Grunwald and Hidalgo, 2003), Sorafenib (Wilhelm et al., 2006), Lapatinib (Wood et al., 2004), Abiraterone (Jarman et al., 1998), Crizotinib (Butrynski et al., 2010) are all approved drugs that have been discovered based on computational drug methods. Until now, the anticancer drug research is rapidly progressing: computational, and AI methods are generating new promising results. As an example, SR13668 is optimized from indole-3-carbinol (I3C) using PH4 design. SR13668 has shown a strong effect on different cancers in phase I (Chao et al., 2007). Recently, Rodrigues et al. have successfully identified a potent inhibitor for 5-lipoxygenase by using machine learning (ML)-based method which was developed from physicochemical and pharmacophore characteristics (Reker et al., 2014; Rodrigues et al., 2018). With the arrival of AI, the design of anticancer drugs in silico has undergone unprecedented changes, and state-of-the-art deep learning approaches have the potential to produce the excellent chemical properties needed for new molecules (Gomez-Bombarelli et al., 2018). Similarly, Jann et al. have developed the first ML-based anti-cancer compound generator using variational autoencoders (VAEs) and have demonstrated that the compound production may be selective toward molecules with high predicted inhibition to a specific cancer (Born et al., 2019). This implied that models could be developed to yield drug candidates with highly desired efficacy $\left(\mathrm{IC}_{50}\right)$ against a target of interest. This breakthrough could transform the design of anticancer drugs in silico by taking advantage of the bimolecular features of the disease to improve the success rate of lead compound discovery.

\section{SUCCESSFUL STORIES OF COMPUTATIONAL DRUG DISCOVERY}

Computational methods have proved to play an essential role in modern drug discovery. Since computational methods could cover almost all stages of the drug discovery pipeline, the applications of computational methods in anticancer drug discoveries have shown great advantages in terms of the required investment, resources, and time. More recently, computational methods have become a potent and powerful tool in several successful cases of anticancer drug development. Herein, we list several successful applications of computational methods for small molecule drugs, which have been applied to cancer treatment or are at later stages in the clinical trial.

The development of Crizotinib is a successful example of applying structure-based design techniques (Cui et al., 2011; Kung et al., 2015). Crizotinib has been considered as a selective and potent cMet/ALK dual inhibitor, which was approved by FDA in 2011 (Cui et al., 2013). c-Met, also known as HGFR (hepatocyte growth factor receptor), and its corresponding natural ligand HGF (hepatocyte growth factor) play a critical role in different cell activities (Christensen et al., 2005). The over-expression of c-Met protein has been often detected in human

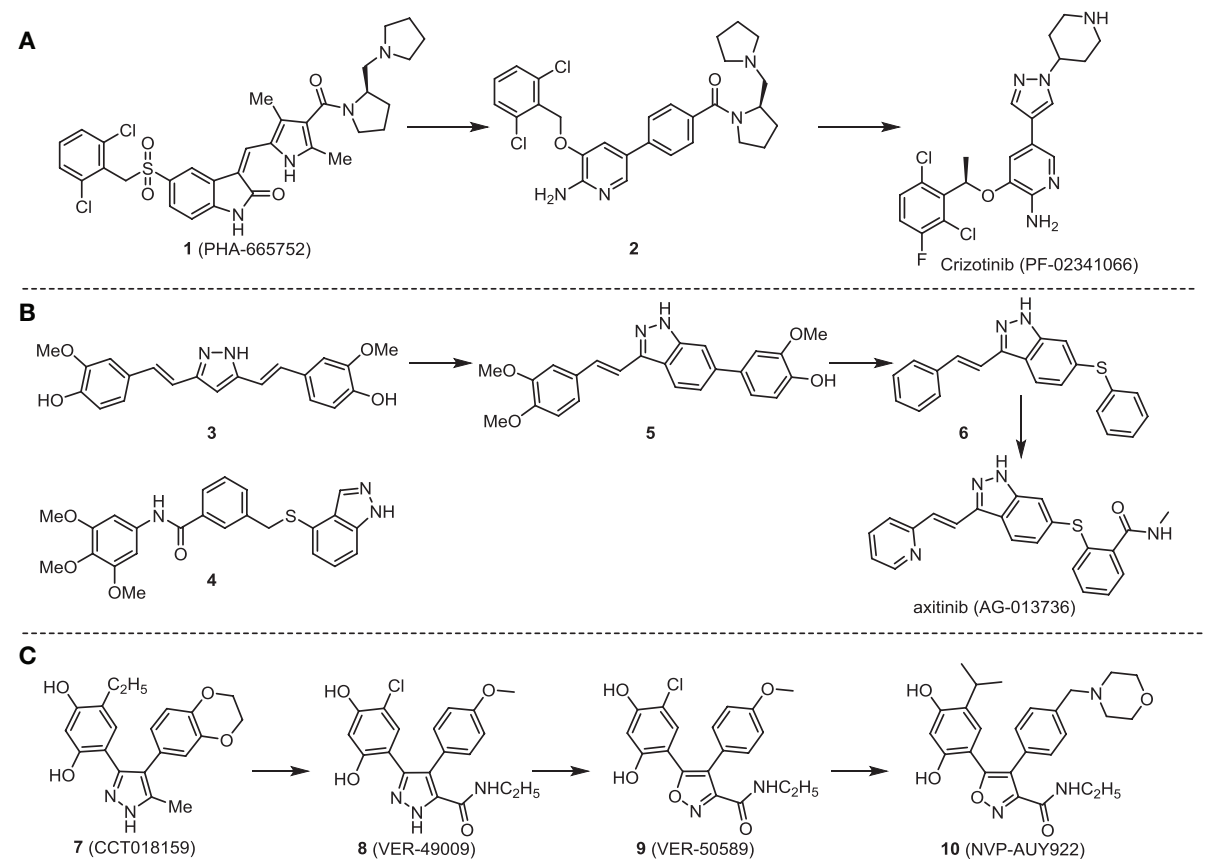

SCHEME 1 | Successful applications of computational methods in anti-cancer drug discovery. 
cancers (including SCLC and NSCLC) (Bottaro et al., 1991; Liu et al., 2008), and abnormal function of c-Met signaling was observed in various solid and blood tumor cancers. Thus, c-MET is an attractive and promising oncology target.

The investigation started with evaluating a series of 3-substituted indolin-2-ones, a potent class of kinase inhibitors, indolin-2-one derivatives for c-MET inhibition. Among the derivatives, compound 1 (PHA-665752, Scheme 1) showed strong activity against the c-MET autophosphorylation process and the corresponding biological activations both in vitro and in vivo. However, the bad drug-like characteristics of compound 1 (PHA665752) limited its further study. The co-crystal structure analysis of compound 1 with the kinase domain of c-MET elucidated the key inhibitor binding site, presenting opportunities for more efficient drug designs. In combination with re-designing the central rings of compound 1 (PHA-665752), a new set of 5-substituted 3benzyloxy-2-aminopyridine series has been developed. Among these newly designed derivatives, compound 2 displayed promising inhibition against c-MET. It is noted that lipophilic efficiency (LipE) was employed as the parameter for the binding effectiveness to monitor the progress of optimization. To further improve the c-Met inhibitory potency, a docked structure of compound 2 with the c-Met kinase domain was carried out to guide the application of structure-based design techniques. Followed by optimization of 3-benzyloxy group, the functional group at 5-position of the 2-aminopyridine, and examination of the chiral center, crizotinib (PF-02341066) with effective tumor growth inhibition and good drug performance has been achieved (see Scheme 1A). Moreover, Crizotinib has demonstrated remarkable clinical efficacy on c-MET gene amplification against lung cancer, lymphoma, and esophageal cancers (Cui et al., 2011; Lennerz et al., 2011; Schwab et al., 2014).

In 2012, Axitinib (AG-013736) was approved by the FDA as as a new therapy for advanced renal cell carcinoma (Meadows and Hurwitz, 2012) to treat VEHG. Axitinib was developed with a structure-based drug design strategy and served as an inhibitor by binding to the VEGF kinase domain in the DFG-out conformation (Kania, 2009; Kania et al., 2016). The VEGF (vascular endothelial growth factor) family functions as important regulators of many signaling networks which involves in angiogenesis. VEGF signaling was identified in tumor cells, and the VEGF signaling plays a crucial role in the development of malignant diseases. As the key receptors of VEGF, VEGFRs serve as ligands in the VEGF signaling network. The VEGF receptors are known as a class of the tyrosine kinases (RTKs), including VEGFR-1 (also called FLT1), VEGFR-2 (also called FLK1 and KDR) and VEGFR-3 (also called FLT4). Blocking the action of VEGFRs with a pan kinase inhibitor against VEGFR-1, VEGFR-2, and VEGFR-3 has been proved to be an efficient way of anti-angiogenic drug development.

During the developmental process, the crystal structure of phosphorylated construct (p-VEGFR2 250$)$, the resolved structures of inhibitor-VEGFR2 $\triangle 50$ (unphosphorylated kinase) complexes, and robust SAR provided important guidance to the rational drug design (Kania, 2009). Combining with the complex structure information, a collection of compounds has been evaluated, generating pyrazoles 3 and benzamide 4 as the starting point for the drug design. Further efforts have been made by the modeling of pyrazole 3 into the ligand-free p-VEGFR $2 \Delta 50$ structure to modify the conformation of pyrazole 3 further, leading to the generation of indazole compounds as novel kinase inhibitors. Among these derivatives, compound 5 with a styryl functional group at the 3-position of the indazole ring was identified to exhibit potent inhibitory effect (Ki of $0.3 \mathrm{nM}$ ), with a high level of LipE and LE. The crystal structure of VEGFR2 $\Delta 50$ with compound 5 revealed the detailed enzyme-ligand mode, showing the indazole core binding to the "open" DFG-in conformation of VEGFR2 $\Delta 50$. Superimposing the other two VEGFR2 $\Delta 50$-inhibitor co-crystal complex structures demonstrated a more precise $3 \mathrm{D}$ structure of the key binding sites for the induction of the DFG-out conformation. Inspired by the superposition result, a chimera design protocol was applied for the subsequent design to capture the above described inhibitor interactions, giving access to 6-sulfur linked indazole compound 6 and the corresponding amide analogs. Further studies on the overlay of VEGFR2 $\Delta 50$ bound co-crystal structures of benzamide 4 and indazole 6 demonstrated that an additional amide group on the orthosteric site of S-phenyl group would help to make the two important hydrogen bonds with the hydrogen bonding groups from Glu885 and Asp1046 of VEGFR2 $\triangle 50$ and provide highly potent inhibitors. Further applying the truncation strategy generated axitinib (AG-013736) (see Scheme 1B), which exhibited a remarkable improvement on cellular potency, desirable physiochemical, and PK properties. Very recently, axitinib (Inlyta ${ }^{\circledR}$ ), in combination with pembrolizumab $\left(\right.$ KEYTRUDA $\left.^{\circledR}\right)$, was approved as the first-line anticancer drug against renal cell carcinoma (RCC)(Atkins et al., 2018).

Heat shock protein 90 (HSP90) has direct and essential effects on the correct performance of different proteins with their activation, conformation, stabilization, and localization functions, whose alterations are associated with cancer development. Thus, HSP90 has become a promising target for cancer treatment (Whitesell and Lindquist, 2005; Pearl and Prodromou, 2006; Sharp and Workman, 2006; Workman et al., 2007). The biological functions of HSP90 have been identified. Its crystal structures indicated that HSP90 has four functional domains: a middle domain, an N-term domain, ATP/ADPbinding domain, and a C-term dimerization domain (Pearl and Prodromou, 2006). Based on the structural information of HSP90, a high-throughput screening was conducted which generated the active drug inhibitor: compound 7 (CCT018159) (Cheung et al., 2005; Smith et al., 2006; Sharp et al., 2007). The subsequently obtained co-crystal structure of HSP90-compound 7 (CCT018159) complex revealed that further modification of compound 7 (CСT018159) by replacing or adding certain functional groups could improve the pharmacokinetic properties. Moreover, replacing the methyl group to an amide group (VER-49009), changing pyrazolyl ring to isoxazole aromatic ring (VER-50589), and modifying some other chemical groups (see Scheme 1C) led to a potent effect in animal cancer models. Followed by toxicology and safety evaluation, Luminespib (NVP-AUY922) has been proved to be a strong HSP90 inhibitor which is now in clinical trials. More 
TABLE 3 | The list of FDA-approved anticancer drugs in recent 3 years from the National Cancer Institute database.

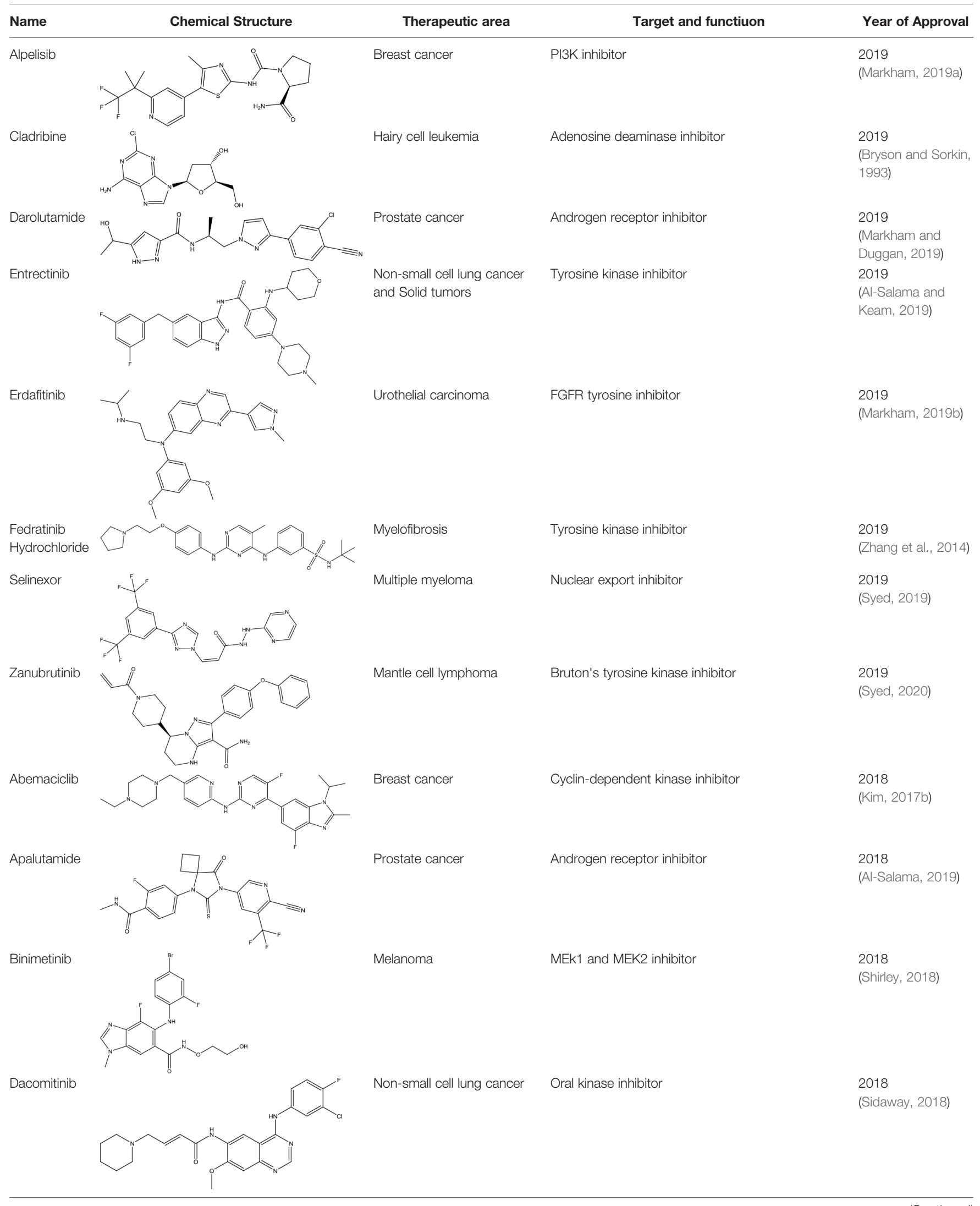


TABLE 3 | Continued

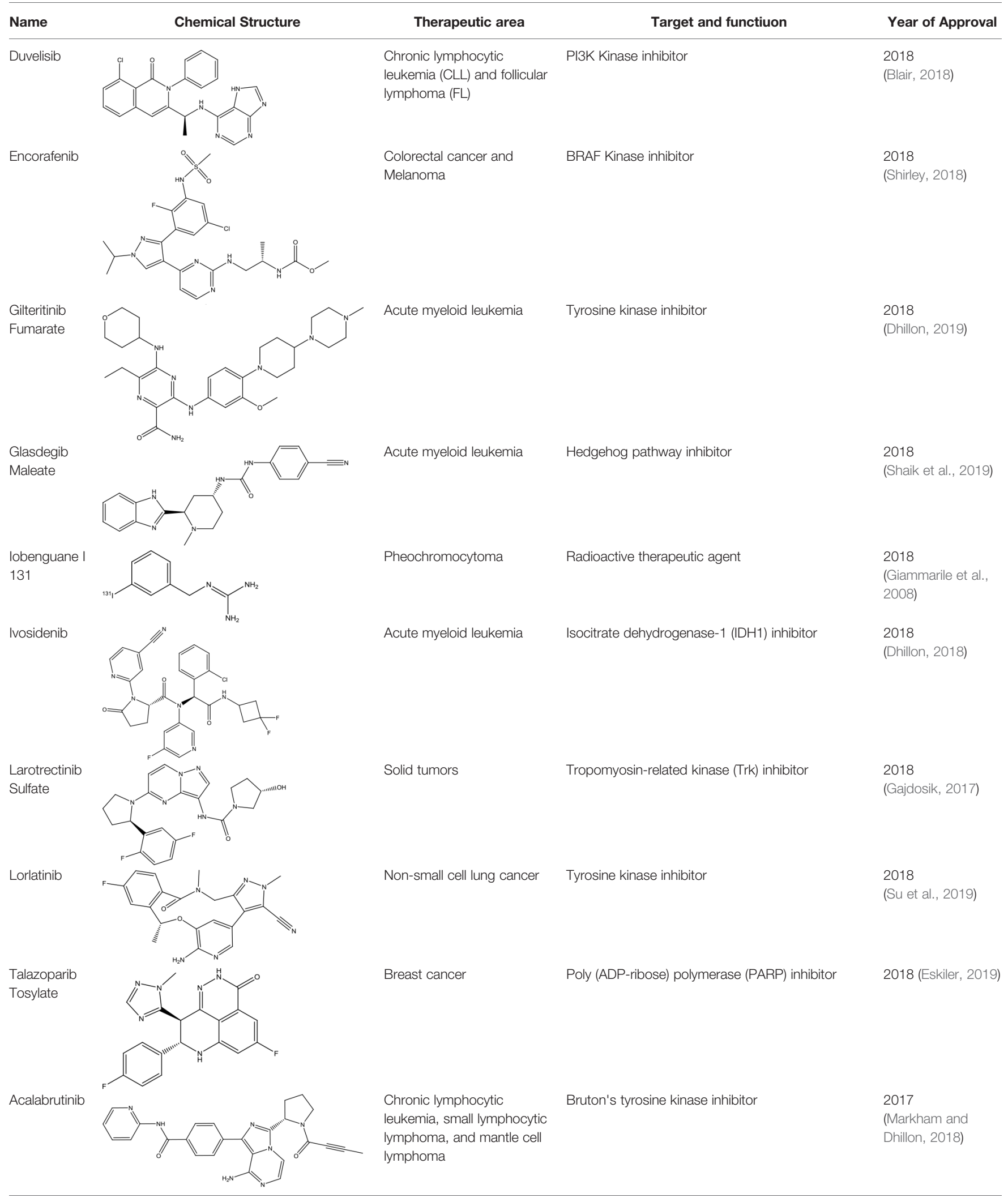


TABLE 3 | Continued

\begin{tabular}{|c|c|c|c|c|}
\hline Name & Chemical Structure & Therapeutic area & Target and functiuon & Year of Approval \\
\hline Midostaurin & & Acute myeloid leukemia & Synthetic indolocarbazole multikinase inhibitor & $\begin{array}{l}2017 \\
(\text { Kim, 2017a) }\end{array}$ \\
\hline $\begin{array}{l}\text { Neratinib } \\
\text { Maleate }\end{array}$ & & Breast cancer & $\begin{array}{l}\text { Receptor tyrosine kinases (RTKs), Human } \\
\text { epidermal growth factor receptor } 2 \text { (HER2; ERBB2), } \\
\text { and Human epidermal growth factor receptor } \\
\text { (EGFR) inhibitor }\end{array}$ & $\begin{array}{l}2017 \\
\text { (Kotecki et al., } \\
\text { 2019) }\end{array}$ \\
\hline Ribociclib & & Breast cancer & Cyclin-dependent kinase (CDK) inhibitor & $\begin{array}{l}2017 \\
\text { (Syed, 2017) }\end{array}$ \\
\hline
\end{tabular}

We further manually screened the database to remove drugs that do not directly target cancer. Drugs for ameliorating conditions related to cancer or limiting side effects of cancer therapies are not listed in this short list. We then identified the FDA label of the drugs in the shortlist by searching in the U.S. National Library of Medicine database "DailyMed". The FDA approval date, drug function, and therapeutic area are retrieved from DailyMed database.

recently, Luminespib, a drug in phase one clinical trials, exhibited positive results for patients with ALK rearrangements (Felip et al., 2018). Luminespib (NVP-AUY922) also exhibited potent anti-tumor activity in lung adenocarcinomas targeting EGFR exon 20 insertion mutations and cellular models in a confirmatory clinical trial (Jorge et al., 2018; Piotrowska et al., 2018). Moreover, Luminespib (NVP-AUY922) serves as one of the components in anticancer combination therapies, which are now at different stages of clinical trials (Garcia-Carbonero et al., 2013; Rong and Yang, 2018). To depict how computational drug discovery facilitates to the development of anticancer drugs, we listed the FDA-approved anticancer drug in recent 3 years which was obtained from National Cancer Institute database (Heller, 1951) in Table 3. 


\section{CONCLUSION AND PERSPECTIVE}

Cancer has become a tangible threat to human health. About 9.6 million people are estimated to die from the various forms of cancer each year, according to a statistic report (Collaborators, 2019). Cancer has become the second-largest disease that causes human death (Reimann et al., 2020). However, developing a new drug molecule costs 12 years and 2.7 billion USD on average (Hauser et al., 2017). The drug development for cancer even becomes more complicated, especially considering the molecular pharmacology is still not well understood. Hence, the discovery and development of new drugs is considered very expensive and time-consuming. In this respect, computational methods could be constructive for performing different tasks including proteininteraction network analysis, drug-target prediction, binding site prediction, virtual screening, and many others. All these innovative methods could considerably facilitate the anti-cancer drug discovery. In recent years, with the advance of AI, more

\section{REFERENCES}

Al-Salama, Z. T., and Keam, S. J. (2019). Entrectinib: first global approval. Drugs 79, 1477-1483. doi: 10.1007/s40265-019-01177-y

Al-Salama, Z. T. (2019). Apalutamide: A Review in Non-Metastatic CastrationResistant Prostate Cancer. Drugs 79, 1591-1598. doi: 10.1007/s40265-01901194-x

Anthony, C. S., Masuyer, G., Sturrock, E. D., and Acharya, K. R. (2012). Structure Based Drug Design of Angiotensin-I Converting Enzyme Inhibitors. Curr. Med. Chem. 19, 845-855. doi: 10.2174/092986712799034950

Atkins, M. B., Plimack, E. R., Puzanov, I., Fishman, M. N., Mcdermott, D. F., Cho, D. C., et al. (2018). Axitinib in combination with pembrolizumab in patients with advanced renal cell cancer: a non-randomised, open-label, dose-finding, and dose-expansion phase 1b trial. Lancet Oncol. 19, 405-415. doi: 10.1016/ S1470-2045(18)30081-0

Blair, H. A. (2018). Duvelisib: First global approval. Drugs 78, 1847-1853. doi: 10.1007/s40265-018-1013-4

Bohm, H. J. (1992). The computer program LUDI: a new method for the de novo design of enzyme inhibitors. J. Comp. Aided Mol. Design 6, 61-78. doi: 10.1007/ BF00124387

Bologa, C. G., Revankar, C. M., Young, S. M., Edwards, B. S., Arterburn, J. B., Kiselyov, A. S., et al. (2006). Virtual and biomolecular screening converge on a selective agonist for GPR30. Nat. Chem. Biol. 2, 207-212. doi: 10.1038/ nchembio775

Born, J., Manica, M., Oskooei, A., and Rodriguez Martínez, M. (2019). PaccMannRL: Designing anticancer drugs from transcriptomic data via reinforcement learning. New York: Cornell University Press.

Bottaro, D. P., Rubin, J. S., Faletto, D. L., Chan, A. M., Kmiecik, T. E., Vande Woude, G. F., et al. (1991). Identification of the hepatocyte growth factor receptor as the c-met proto-oncogene product. Sci. (New York N.Y.) 251, 802804. doi: $10.1126 /$ science. 1846706

Bray, F., Ferlay, J., Soerjomataram, I., Siegel, R. L., Torre, L. A., and Jemal, A. (2018). Global cancer statistics 2018: GLOBOCAN estimates of incidence and mortality worldwide for 36 cancers in 185 countries. Ca-a Cancer J. Clin. 68, 394-424. doi: 10.3322/caac. 21492

Bryson, H. M., and Sorkin, E. M. (1993). Cladribine-A review of its pharmacodynamic and pharmacokinetic properties and therapeutic potential in hematological malignancies. Drugs 46, 872-894. doi: 10.2165/00003495199346050-00007

Buckle, D. R., Erhardt, P. W., Ganellin, C. R., Kobayashi, T., Perun, T. J., Proudfoot, J., et al. (2013). Glossary of terms used in medicinal chemistry. Part II (IUPAC Recommendations 2013). Pure Appl. Chem. 85, 1725-1758. doi: 10.1351/PAC-REC-12-11-23 sophisticated methods, such as retro-synthetic routine plan, drug scaffold generation, drug binding affinity predictions, were developed. The useful predictions generated by computational models combined with experimental validations could further speed up the anti-cancer drug development.

\section{AUTHOR CONTRIBUTIONS}

SY designed the whole review. WC directed the completion of the review. AA, SW, QY, and YL were supportive during the review.

\section{FUNDING}

This work was supported by the internal funding of Shenzhen Institutes of Advanced Technology, Chinese Academy of Sciences.

Butrynski, J. E., D'adamo, D. R., Hornick, J. L., Dal Cin, P., Antonescu, C. R., Jhanwar, S. C., et al. (2010). Crizotinib in ALK-Rearranged Inflammatory Myofibroblastic Tumor. New Engl. J. Med. 363, 1727-1733. doi: 10.1056/NEJMoa1007056

Campillos, M., Kuhn, M., Gavin, A.-C., Jensen, L. J., and Bork, P. (2008). Drug target identification using side-effect similarity. Science 321, 263-266. doi: $10.1126 /$ science. 1158140

Chan, H. C. S., Wang, J., Palczewski, K., Filipek, S., Vogel, H., Liu, Z.-J., et al. (2018). Exploring a new ligand binding site of $\mathrm{G}$ proteincoupled receptors. Chem. Sci. 9, 11. doi: 10.1039/C8SC01680A

Chan, H. C. S., Shan, H., Dahoun, T., Vogel, H., and Yuan, S. (2019). Advancing Drug Discovery via Artificial Intelligence. Trends Pharmacol. Sci. 40, 592-604. doi: 10.1016/j.tips.2019.06.004

Chan, H. C. S., Xu, Y., Tan, L., Vogel, H., Cheng, J., Wu, D., et al. (2020). Enhancing the Signaling of GPCRs via Orthosteric Ions. ACS Cent. Sci. 6, 274282. doi: 10.1021/acscentsci.9b01247

Chao, W.-R., Yean, D., Amin, K., Green, C., and Jong, L. (2007). Computer-aided rational drug design: A novel agent (SR13668) designed to mimic the unique anticancer mechanisms of dietary indole-3-carbinol to block akt signaling. J. Med. Chem. 50, 3412-3415. doi: 10.1021/jm070040e

Chen, J., and Lai, L. (2006). Pocket v.2: Further developments on receptor-based pharmacophore modeling. J. Chem. Inf. Model. 46, 2684-2691. doi: 10.1021/ ci600246s

Chen, X., Liu, M.-X., and Yan, G.-Y. (2012). Drug-target interaction prediction by random walk on the heterogeneous network. Mol. Biosyst. 8, 1970-1978. doi: $10.1039 / \mathrm{c} 2 \mathrm{mb} 00002 \mathrm{~d}$

Chen, X., Yan, C. C., Zhang, X., Zhang, X., Dai, F., Yin, J., et al. (2016). Drug-target interaction prediction: databases, web servers and computational models. Briefings Bioinf. 17, 696-712. doi: 10.1093/bib/bbv066

Cheung, K. M. J., Matthews, T. P., James, K., Rowlands, M. G., Boxall, K. J., Sharp, S. Y. et al. (2005). The identification, synthesis, protein crystal structure and in vitro biochemical evaluation of a new 3,4-diarylpyrazole class of Hsp90 inhibitors. Bioorg. Med. Chem. Lett. 15, 3338-3343. doi: 10.1016/j.bmcl.2005.05.046

Chiang, Y. K., Kuo, C. C., Wu, Y. S., Chen, C. T., Coumar, M. S., Wu, J. S., et al. (2009). Generation of Ligand-Based Pharmacophore Model and Virtual Screening for Identification of Novel Tubulin Inhibitors with Potent Anticancer Activity. I. Med. Chem. 52, 4221-4233. doi: 10.1021/ jm801649y

Christensen, J. G., Burrows, J., and Salgia, R. (2005). c-Met as a target for human cancer and characterization of inhibitors for therapeutic intervention. Cancer Lett. 225, 1-26. doi: 10.1016/j.canlet.2004.09.044

Collaborators, G.B.D.S (2019). Global, regional, and national burden of stroke 1990-2016: a systematic analysis for the Global Burden of Disease Study 2016. Lancet Neurol. 18, 439-458, doi: 10.1016/s1474-4422(19)30034-1 
Conn, P. J., Christopoulos, A., and Lindsley, C. W. (2009). Allosteric modulators of GPCRs: a novel approach for the treatment of CNS disorders. Nat. Rev. Drug Discovery 8, 41-54. doi: 10.1038/nrd2760

Cramer, R. D., Patterson, D. E., and Bunce, J. D. (1988). Comparative molecular field analysis (CoMFA). 1. Effect of shape on binding of steroids to carrier proteins. J. Am. Chem. Soc. 110, 5959-5967. doi: 10.1021/ja00226a005

Cui, J. J., Tran-Dube, M., Shen, H., Nambu, M., Kung, P.-P., Pairish, M., et al. (2011). Structure Based Drug Design of Crizotinib (PF-02341066), a Potent and Selective Dual Inhibitor of Mesenchymal-Epithelial Transition Factor (cMET) Kinase and Anaplastic Lymphoma Kinase (ALK). J. Med. Chem. 54, 6342-6363. doi: 10.1021/jm2007613

Cui, J. J., Mctigue, M., Kania, R., and Edwards, M. (2013). Case History: XalkoriTM (Crizotinib), a Potent and Selective Dual Inhibitor of Mesenchymal Epithelial Transition (MET) and Anaplastic Lymphoma Kinase (ALK) for Cancer Treatment.Annu. Rep. Med. Chem. 48, 421-434. doi: 10.1016/b978-0-12-417150-3.00025-9

Cuzzolin, A., Sturlese, M., Deganutti, G., Salmaso, V., Sabbadin, D., Ciancetta, A., et al. (2016). Deciphering the Complexity of Ligand-Protein Recognition Pathways Using Supervised Molecular Dynamics (SuMD) Simulations. J. Chem. Inf. Model. 56, 687-705. doi: 10.1021/acs.jcim.5b00702

Debnath, S., Kanakaraju, M., Islam, M., Yeeravalli, R., Sen, D., and Das, A. (2019). In silico design, synthesis and activity of potential drug-like chrysin scaffoldderived selective EGFR inhibitors as anticancer agents. Comput. Biol. Chem. 83. doi: 10.1016/j.compbiolchem.2019.107156

Deganutti, G., Cuzzolin, A., Ciancetta, A., and Moro, S. (2015). Understanding allosteric interactions in $G$ protein-coupled receptors using Supervised Molecular Dynamics: A prototype study analysing the human A(3) adenosine receptor positive allosteric modulator LUF6000. Bioorg. Med. Chem. 23, 4065-4071. doi: 10.1016/j.bmc.2015.03.039

Devree, B. T., Mahoney, J. P., Velez-Ruiz, G. A., Rasmussen, S. G. F., Kuszak, A. J., Edwald, E., et al. (2016). Allosteric coupling from $G$ protein to the agonistbinding pocket in GPCRs. Nature 535, 182-18+. doi: 10.1038/nature18324

Dhillon, S. (2018). Ivosidenib: First Global Approval. Drugs 78, 1509-1516. doi: 10.1007/s40265-018-0978-3

Dhillon, S. (2019). Gilteritinib: First Global Approval. Drugs 79, 331-339. doi: 10.1007/s40265-019-1062-3

Dias, R., and De Azevedo, W. F.Jr. (2008). Molecular Docking Algorithms. Curr. Drug Targets 9, 1040-1047. doi: 10.2174/138945008786949432

Drews, J. (2000). Drug discovery: a historical perspective. Sci. (New York N.Y.) 287, 1960-1964. doi: 10.1126/science.287.5460.1960

Eskiler, G. G. (2019). Talazoparib to treat BRCA-positive breast cancer. Drugs Today 55, 459-467. doi: 10.1358/dot.2019.55.7.3015642

Felip, E., Barlesi, F., Besse, B., Chu, Q., Gandhi, L., Kim, S.-W., et al. (2018). Phase 2 Study of the HSP-90 Inhibitor AUY922 in Previously Treated and Molecularly Defined Patients with Advanced Non-Small Cell Lung Cancer. J. Thoracic Oncol. 13, 576-584. doi: 10.1016/j.jtho.2017.11.131

Ferreira, L. G., Dos Santos, R. N., Oliva, G., and Andricopulo, A. D. (2015). Molecular Docking and Structure-Based Drug Design Strategies. Molecules 20, 13384-13421. doi: 10.3390/molecules200713384

Flock, T., Ravarani, C. N. J., Sun, D., Venkatakrishnan, A. J., Kayikci, M., Tate, C. G., et al. (2015). Universal allosteric mechanism for $\mathrm{G}$ alpha activation by GPCRs. Nature 524, 173-17+. doi: 10.1038/nature14663

Gajdosik, Z. (2017). Larotrectinib sulfate. Drugs Future 42, 275-280. doi: 10.1358/ dof.2017.042.05.2623108

Garcia-Carbonero, R., Carnero, A., and Paz-Ares, L. (2013). Inhibition of HSP90 molecular chaperones: moving into the clinic. Lancet Oncol. 14, E358-E369. doi: 10.1016/S1470-2045(13)70169-4

Ghofrani, H. A., Osterloh, I. H., and Grimminger, F. (2006). Sildenafil: from angina to erectile dysfunction to pulmonary hypertension and beyond. Nat. Rev. Drug Discovery 5, 689-702. doi: 10.1038/nrd2030

Giammarile, F., Chiti, A., Lassmann, M., Brans, B., and Flux, G. (2008). EANM procedure guidelines for I-131-meta-iodobenzylguanidine (I-131-mIBG) therapy. Eur. J. Nuclear Med. Mol. Imaging 35, 1039-1047. doi: 10.1007/ s00259-008-0715-3

Gomez-Bombarelli, R., Wei, J. N., Duvenaud, D., Hernandez-Lobato, J. M., Sanchez-Lengeling, B., Sheberla, D., et al. (2018). Automatic Chemical Design Using a Data-Driven Continuous Representation of Molecules. ACS Cent. Sci. 4, 268-276. doi: 10.1021/acscentsci.7b00572
Gras, J. (2017). Enasidenib mesylate. Drugs Future 42, 15-20. doi: 10.1358/ dof.2017.042.01.2579894

Grunwald, V., and Hidalgo, M. (2003). Development of the epidermal growth factor receptor inhibitor Tarceva (TM) (OSI-774). New Trends in Cancer for the 21st Century. 235-246. doi: 10.1007/978-1-4615-0081-0_19

Halperin, I., Ma, B., Wolfson, H., and Nussinov, R. (2002). Principles of docking: An overview of search algorithms and a guide to scoring functions. Proteins 47, 409-443. doi: 10.1002/prot.10115

Hancock, J. F. (2003). Ras proteins: Different signals from different locations. Nat. Rev. Mol. Cell Biol. 4, 373-384. doi: 10.1038/nrm1105

Hansch, C., and Fujita, T. (1964). Additions and Corrections- $\rho-\sigma-\pi$ Analysis. A Method for the Correlation of Biological Activity and Chemical Structure. J. Am. Chem. Soc. 86, 5710-5710. doi: 10.1021/ja01078a623

Hauser, A. S., Attwood, M. M., Rask-Andersen, M., Schioth, H. B., and Gloriam, D. E. (2017). Trends in GPCR drug discovery: new agents, targets and indications. Nat. Rev. Drug Discovery 16, 829-842. doi: 10.1038/nrd.2017.178

Heller, J.R. (1951). National Canaer Institute. JAMA-J. Am. Med. Assoc. 146, 1248 1248. doi: 10.1001/jama.1951.03670130070024

Hong, J. Y., Price, I. R., Bai, J. J., and Lie, H. (2019). A Glycoconjugated SIRT2 Inhibitor with Aqueous Solubility Allows Structure-Based Design of SIRT2 Inhibitors. ACS Chem. Biol. 14, 1802-1810. doi: 10.1021/acschembio.9b00384

Hopkins, A. L. (2008). Network pharmacology: the next paradigm in drug discovery. Nat. Chem. Biol. 4, 682-690. doi: 10.1038/nchembio.118

Hu, G., Kuang, G., Xiao, W., Li, W., Liu, G., and Tang, Y. (2012). Performance Evaluation of 2D Fingerprint and 3D Shape Similarity Methods in Virtual Screening. J. Chem. Inf. Model. 52, 1103-1113. doi: 10.1021/ci300030u

Huang, S.-Y., Grinter, S. Z., and Zou, X. (2010). Scoring functions and their evaluation methods for protein-ligand docking: recent advances and future directions. Phys. Chem. Chem. Phys. 12, 12899-12908. doi: 10.1039/ c0cp00151a

Itoh, Y. (2020). Drug Discovery Researches on Modulators of Lysine-Modifying Enzymes Based on Strategic Chemistry Approaches. Chem. Pharmaceut. Bull. 68, 34-45. doi: 10.1248/cpb.c19-00741

Jarman, M., Barrie, S. E., and Llera, J. M. (1998). The 16,17-double bond is needed for irreversible inhibition of human cytochrome $\mathrm{P} 450$ (17 alpha) by abiraterone (17-(3-pyridyl)androsta-5,16-dien-3 beta-ol) and related steroidal inhibitors. J. Med. Chem. 41, 5375-5381. doi: 10.1021/jm981017j

Jorge, S. E., Lucena-Araujo, A. R., Yasuda, H., Piotrowska, Z., Oxnard, G. R., Rangachari, D., et al. (2018). EGFR Exon 20 Insertion Mutations Display Sensitivity to Hsp90 Inhibition in Preclinical Models and Lung Adenocarcinomas. Clin. Cancer Res. 24, 6548-6555. doi: 10.1158/10780432.CCR-18-1541

Kaldor, S. W., Kalish, V. J., Davies, J. F., Shetty, B. V., Fritz, J. E., Appelt, K., et al. (1997). Viracept (nelfinavir mesylate, AG1343): A potent, orally bioavailable inhibitor of HIV-1 protease. J. Med. Chem. 40, 3979-3985. doi: 10.1021/jm9704098

Kania, R. S., Bender, S. L., Borchardt, A. J., Cripps, S. J., Hua, Y., Johnson, M. D., et al. (2016) Indazole compounds and pharmaceutical compositions for Inhibiting protein kinases, and methods for their use [Accessed November 28, 2006].

Kania, R. (2009). "Structure-Based Design and Characterization of Axitinib. Kinase Inhibitor Drugs, Drug Discovery and Development. Eds. R. Li and J. A. Stafford (New York: Wiley).

Kapetanovic, I. M. (2008). Computer-aided drug discovery and development (CADDD): In silico-chemico-biological approach. Chem. Biol. Interact. 171, 165-176. doi: 10.1016/j.cbi.2006.12.006

Kim, E. S. (2017a). Midostaurin: First Global Approval. Drugs 77, 1251-1259. doi: 10.1007/s40265-017-0779-0

Kim, E. S. (2017b). Abemaciclib: first global approval. Drugs 77, 2063-2070. doi: 10.1007/s40265-017-0840-z

Klebe, G., Abraham, U., and Mietzner, T. (1994). Molecular similarity indices in a comparative analysis (CoMSIA) of drug molecules to correlate and predict their biological activity. J. Med. Chem. 37, 4130-4146. doi: 10.1021/ jm00050a010

Klipp, E., Wade, R. C., and Kummer, U. (2010). Biochemical network-based drugtarget prediction. Curr. Opin. Biotechnol. 21, 511-516. doi: 10.1016/ j.copbio.2010.05.004

Kortagere, S., and Ekins, S. (2010). Troubleshooting computational methods in drug discovery. J. Pharmacol. Toxicol. Methods 61, 67-75. doi: 10.1016/ j.vascn.2010.02.005 
Kotecki, N., Gombos, A., and Awada, A. (2019). Adjuvant therapeutic approaches of HER2-positive breast cancer with a focus on neratinib maleate. Expert Rev. Anticancer Ther. 19, 447-454. doi: 10.1080/14737140.2019.1613892

Kung, P. P., Jones, R. A., and Richardson, P. (2015). Crizotinib (Xalkori): The Firstin-Class ALK/ROS Inhibitor for Non-small Cell Lung Cancer (Inc: John Wiley \& Sons).

Lazo, J. S., and Sharlow, E. R. (2016). Drugging Undruggable Molecular Cancer Targets.. Annu. Rev. Phar. Toxicol. 56, 23-40. doi: 10.1146/annurev-pharmtox010715-103440

Lennerz, J. K., Kwak, E. L., Ackerman, A., Michael, M., Fox, S. B., Bergethon, K., et al. (2011). MET Amplification Identifies a Small and Aggressive Subgroup of Esophagogastric Adenocarcinoma With Evidence of Responsiveness to Crizotinib. J. Clin. Oncol. 29, 4803-4810. doi: 10.1200/JCO.2011.35.4928

Li, X., and Chen, H. C. (2013). Recommendation as link prediction in bipartite graphs: A graph kernel-based machine learning approach. Decision Support Syst. 54, 880-890. doi: 10.1016/j.dss.2012.09.019

Liu, X., Yao, W., Newton, R. C., and Scherle, P. A. (2008). Targeting the c-MET signaling pathway for cancer therapy. Expert Opin. Investigational Drugs 17, 997-1011. doi: 10.1517/13543784.17.7.997

Lu, P., Bevan, D. R., Leber, A., Hontecillas, R., Tubau-Juni, N., and BassaganyaRiera, J. (2018a). "Computer-aided drug discovery," in Accelerated Path to Cures (Springer), 7-24. doi: 10.1007/978-3-319-73238-1_2

Lu, X., Yang, H., Chen, Y., Li, Q., He, S.-Y., Jiang, X., et al. (2018b). The Development of Pharmacophore Modeling: Generation and Recent Applications in Drug Discovery. Curr. Pharmaceut. Design 24, 3424-3439. doi: $10.2174 / 1381612824666180810162944$

Markham, A., and Dhillon, S. (2018). Acalabrutinib: First Global Approval. Drugs 78, 139-145. doi: 10.1007/s40265-017-0852-8

Markham, A., and Duggan, S. (2019). Darolutamide: First Approval. Drugs 79, 1813-1818. doi: 10.1007/s40265-019-01212-y

Markham, A. (2017a). Brigatinib: First Global Approval. Drugs 77, 1131-1135. doi: 10.1007/s40265-017-0776-3

Markham, A. (2017b). Copanlisib: First Global Approval. Drugs 77, 2057-2062. doi: 10.1007/s40265-017-0838-6

Markham, A. (2019a). Alpelisib: first global approval. Drugs 79, 1249-1253. doi: 10.1007/s40265-019-01161-6

Markham, A. (2019b). Erdafitinib: First Global Approval 79, 1017-1021. doi: 10.1007/s40265-019-01142-9

Mathi, P., Prasad, M. V., Botlagunta, M., Ravi, M., and Ramachandran, D. (2018). De novo design of selective Sortase-A inhibitors: Synthesis, structural and in vitro characterization. Chem. Data Collect. 15, 126-133. doi: 10.1016/ j.cdc.2018.04.007

Mayr, A., Klambauer, G., Unterthiner, T., Steijaert, M., Wegner, J. K., Ceulemans, H., et al. (2018). Large-scale comparison of machine learning methods for drug target prediction on ChEMBL. Chem. Sci. 9, 5441-5451. doi: 10.1039/ C8SC00148K

Mazmanian, S. K., Liu, G., Ton-That, H., and Schneewind, O. (1999). Staphylococcus aureus sortase, an enzyme that anchors surface proteins to the cell wall. Sci. (New York N.Y.) 285, 760-763. doi: 10.1126/ science.285.5428.760

Meadows, K. L., and Hurwitz, H. I. (2012). Anti-VEGF Therapies in the Clinic. Cold Spring Harbor Perspect. Med. 2, 27. doi: 10.1101/cshperspect.a006577

Mendenhall, J., and Meiler, J. (2016). Improving quantitative structure-activity relationship models using Artificial Neural Networks trained with dropout. J. Comp. Aided Mol. Design 30, 177-189. doi: 10.1007/s10822-016-9895-2

Mendoza, J. L., Escalante, N. K., Jude, K. M., Bellon, J. S., Su, L., Horton, T. M., et al. (2019). Structure of the IFN gamma receptor complex guides design of biased agonists. Nature 567, 56-5+. doi: 10.1038/s41586-019-0988-7

Mittica, G., Ghisoni, E., Giannone, G., Genta, S., Aglietta, M., Sapino, A., et al (2018). PARP Inhibitors in Ovarian Cancer. Recent Pat. Anticancer Drug Discov. 13, 392-410. doi: 10.2174/1574892813666180305165256

Muhsin, M., Graham, J., and Kirkpatrick, P. (2003). Fresh from the pipeline Gefitinib. Nat. Rev. Drug Discovery 2, 515-516. doi: 10.1038/nrd1136

Ortuso, F., Langer, T., and Alcaro, S. (2006). GBPM: GRID-based pharmacophore model: concept and application studies to protein-protein recognition. Bioinformatics 22, 1449-1455. doi: 10.1093/bioinformatics/btl115
Pearl, L. H., and Prodromou, C. (2006). Structure and mechanism of the Hsp90 molecular chaperone machinery. Annu. Rev. Biochem. 75, 271-294. doi: 10.1146/annurev.biochem.75.103004.142738

Piotrowska, Z., Costa, D. B., Oxnard, G. R., Huberman, M., Gainor, J. F., Lennes, I. T., et al. (2018). Activity of the Hsp90 inhibitor luminespib among non-smallcell lung cancers harboring EGFR exon 20 insertions. Ann. Oncol. 29, 20922097. doi: 10.1093/annonc/mdy336

Pirhadi, S., Shiri, F., and Ghasemi, J. B. (2013). Methods and applications of structure based pharmacophores in drug discovery. Curr. Top. Med. Chem. 13, 1036-1047. doi: 10.2174/1568026611313090006

Prada-Gracia, D., Huerta-Yepez, S., and Moreno-Vargas, L. M. (2016). Application of computational methods for anticancer drug discovery, design, and optimization. Boletin Med. Del Hosp. Infantil. Mexico 73, 411-423. doi: 10.1016/j.bmhimx.2016.10.006

Reimann, Z., Miller, J. R., Dahle, K. M., Hooper, A. P., Young, A. M., Goates, M. C., et al. (2020). Executive functions and health behaviors associated with the leading causes of death in the United States: A systematic review. J. Health Psychol. 25, 186-196. doi: 10.1177/1359105318800829

Reker, D., Rodrigues, T., Schneider, P., and Schneider, G. (2014). Identifying the macromolecular targets of de novo-designed chemical entities through selforganizing map consensus. Proc. Natl. Acad. Sci. United States America 111, 4067-4072. doi: 10.1073/pnas.1320001111

Rodrigues, T., Werner, M., Roth, J., Da Cruz, E. H. G., Marques, M. C., Akkapeddi, P., et al. (2018). Machine intelligence decrypts -lapachone as an allosteric 5lipoxygenase inhibitor. Chem. Sci. 9, 6. doi: 10.1039/c8sc02634c.

Rong, B., and Yang, S. (2018). Molecular mechanism and targeted therapy of Hsp90 involved in lung cancer: New discoveries and developments (Review). Int. J. Oncol. 52, 321-336. doi: 10.3892/ijo.2017.4214

Rush, T. S., Grant, J. A., Mosyak, L., and Nicholls, A. (2005). A Shape-Based 3-D Scaffold Hopping Method and Its Application to a Bacterial Protein?Protein Interaction. J. Med. Chem. 48, 1489-1495. doi: 10.1021/jm040163o

Sabbadin, D., and Moro, S. (2014). Supervised Molecular Dynamics (SuMD) as a Helpful Tool To Depict GPCR-Ligand Recognition Pathway in a Nanosecond Time Scale. J. Chem. Inf. Model. 54, 372-376. doi: 10.1021/ci400766b

Salmaso, V., and Moro, S. (2018). Bridging Molecular Docking to Molecular Dynamics in Exploring Ligand-Protein Recognition Process: An Overview. Front. Pharmacol. 9. doi: 10.3389/fphar.2018.00923

Schwab, R., Petak, I., Kollar, M., Pinter, F., Varkondi, E., Kohanka, A., et al. (2014). Major partial response to crizotinib, a dual MET/ALK inhibitor, in a squamous cell lung (SCC) carcinoma patient with de novo c-MET amplification in the absence of ALK rearrangement. Lung Cancer 83, 109-111. doi: 10.1016/j.lungcan.2013.10.006

Shaik, N., Hee, B., Wei, H., and Labadie, R. R. (2019). Evaluation of the effects of formulation, food, or a proton-pump inhibitor on the pharmacokinetics of glasdegib (PF-04449913) in healthy volunteers: a randomized phase I study. Cancer Chemother. Pharmacol. 83, 463-472. doi: 10.1007/s00280-018-3748-8

Sharp, S., and Workman, P. (2006). Inhibitors of the HSP90 molecular chaperone: Current status. Adv. Cancer Res. 95. doi: 10.1016/s0065-230x(06)95009-x

Sharp, S. Y., Boxall, K., Rowlands, M., Prodromou, C., Roe, S. M., Maloney, A., et al. (2007). In vitro biological characterization of a novel, synthetic diaryl pyrazole resorcinol class of heat shock protein 90 inhibitors. Cancer Res. 67, 2206-2216. doi: 10.1158/0008-5472.CAN-06-3473

Shirley, M. (2018). Encorafenib and Binimetinib: First Global Approvals. Drugs 78, 1277-1284. doi: 10.1007/s40265-018-0963-x

Sidaway, P. (2018). Cemiplimab effective in cutaneous SCC. Nat. Rev. Clin. Oncol. 15, 472-472. doi: 10.1038/s41571-018-0056-5

Smith, N. F., Hayes, A., James, K., Nutley, B. P., Mcdonald, E., Henley, A., et al. (2006). Preclinical pharmacokinetics and metabolism of a novel diaryl pyrazole resorcinol series of heat shock protein 90 inhibitors. Mol. Cancer Ther. 5, 1628 1637. doi: 10.1158/1535-7163.MCT-06-0041

Srivastava, N., Hinton, G., Krizhevsky, A., Sutskever, I., and Salakhutdinov, R. (2014). Dropout: A Simple Way to Prevent Neural Networks from Overfitting. J. Mach. Learn. Res. 15, 1929-1958. doi: 10.5555/2627435.2670313

Su, Y., Long, X., Song, Y., Chen, P., Li, S., Yang, H., et al. (2019). Distribution of ALK Fusion Variants and Correlation with Clinical Outcomes in Chinese Patients with Non-Small Cell Lung Cancer Treated with Crizotinib. Targeted Oncol. 14, 159-168. doi: 10.1007/s11523-019-00631-x 
Syed, Y. Y. (2017). Ribociclib: First Global Approval. Drugs 77, 799-807. doi: $10.1007 /$ s40265-017-0742-0

Syed, Y. Y. (2019). Selinexor: First Global Approval. Drugs 79, 1485-1494. doi: 10.1007/s40265-019-01188-9

Syed, Y. Y. (2020). Zanubrutinib: First Approval. Drugs. 80, 91-97. 1-7. doi: 10.1007/s40265-019-01252-4

Takarabe, M., Kotera, M., Nishimura, Y., Goto, S., and Yamanishi, Y. (2012). Drug target prediction using adverse event report systems: a pharmacogenomic approach. Bioinformatics 28, I611-I618. doi: 10.1093/bioinformatics/bts413

Tautermann, C. S. (2014). GPCR structures in drug design, emerging opportunities with new structures. Bioorg. Med. Chem. Lett. 24, 4073-4079. doi: 10.1016/j.bmcl.2014.07.009

Tondo, A. R., Caputo, L., Mangiatordi, G. F., Monaci, L., Lentini, G., Logrieco, A. F., et al. (2020). Structure-Based Identification and Design of Angiotensin Converting Enzyme-Inhibitory Peptides from Whey Proteins. J. Agric. Food Chem. 68, 541-548. doi: 10.1021/acs.jafc.9b06237

Tong, M., and Seeliger, M. A. (2015). Targeting Conformational Plasticity of Protein Kinases. ACS Chem. Biol. 10, 190-200. doi: 10.1021/cb500870a

Urwyler, S. (2011). Allosteric Modulation of Family C G-Protein-Coupled Receptors: from Molecular Insights to Therapeutic Perspectives. Pharmacol. Rev. 63, 59-126. doi: 10.1124/pr.109.002501

Wang, J. L., Liu, D., Zhang, Z. J., Shan, S., Han, X., Srinivasula, S. M., et al. (2000). Structure-based discovery of an organic compound that binds Bcl-2 protein and induces apoptosis of tumor cells. Proc. Natl. Acad. Sci. United States America 97, 7124-7129. doi: 10.1073/pnas.97.13.7124

Whitesell, L., and Lindquist, S. L. (2005). HSP90 and the chaperoning of cancer. Nat. Rev. Cancer 5, 761-772. doi: 10.1038/nrc1716

Wilhelm, S., Carter, C., Lynch, M., Lowinger, T., Dumas, J., Smith, R. A., et al. (2006). Discovery and development of sorafenib: a multikinase inhibitor for treating cancer. Nat. Rev. Drug Discovery 5, 835-844. doi: 10.1038/nrd2130

Wolber, G., Dornhofer, A. A., and Langer, T. (2006). Efficient overlay of small organic molecules using 3D pharmacophores. J. Comp. Aided Mol. Design 20, 773-788. doi: 10.1007/s10822-006-9078-7

Wood, E. R., Truesdale, A. T., Mcdonald, O. B., Yuan, D., Hassell, A., Dickerson, S. H., et al. (2004). A unique structure for epidermal growth factor receptor bound to GW572016 (Lapatinib): Relationships among protein conformation, inhibitor off-rate, and receptor activity in tumor cells. Cancer Res. 64, 66526659. doi: 10.1158/0008-5472.CAN-04-1168

Workman, P., Burrows, F., Neckers, L., and Rosen, N. (2007). “"'Drugging the cancer chaperone HSP90 combinatorial therapeutic exploitation of oncogene addiction and tumor stress," in Stress Responses in Biology and Medicine: Stress of Life in Molecules, Cells, Organisms, and Psychosocial Communities. Eds. P.
Csermely, T. Korcsmaros and K. Sulyok. 1113, 202-216. doi: 10.1196/ annals.1391.012

Yamanishi, Y., Araki, M., Gutteridge, A., Honda, W., and Kanehisa, M. (2008). Prediction of drug-target interaction networks from the integration of chemical and genomic spaces. Bioinformatics 24, I232-I240. doi: 10.1093/ bioinformatics/btn 162

Yan, B., Yang, W. J., Han, X. Y., and Han, L. H. (2019). Crystal structures and antitumor activity evaluation against gastric carcinoma of two novel coordination polymers. Main Group Chem. 18, 239-246. doi: 10.3233/MGC-180748

Yang, X., Wang, Y., Byrne, R., Schneider, G., and Yang, S. (2019). Concepts of Artificial Intelligence for Computer-Assisted Drug Discovery. Chem. Rev. 119, 10520-10594. doi: 10.1021/acs.chemrev.8b00728

Yang, S.-Y. (2010). Pharmacophore modeling and applications in drug discovery: challenges and recent advances. Drug Discovery Today 15, 444-450. doi: 10.1016/j.drudis.2010.03.013

Yildirim, M. A., Goh, K. I., Cusick, M. E., Barabasi, A. L., and Vidal, M. (2007). Drug-target network. Nat. Biotechnol. 25, 1119-1126. doi: 10.1038/nbt1338

Yuriev, E., Holien, J., and Ramsland, P. A. (2015). Improvements, trends, and new ideas in molecular docking: 2012-2013 in review. J. Mol. Recogn. 28, 581-604. doi: $10.1002 / j m r .2471$

Zhang, Q., Zhang, Y., Diamond, S., Boer, J., Harris, J. J., Li, Y., et al. (2014). The Janus kinase 2 inhibitor fedratinib inhibits thiamine uptake: a putative mechanism for the onset of Wernicke's encephalopathy. Drug Metab. Dispos. 42, 1656-1662. doi: 10.1124/dmd.114.058883

Zhavoronkov, A., Ivanenkov, Y. A., Aliper, A., Veselov, M. S., Aladinskiy, V. A., Aladinskaya, A. V., et al. (2019). Deep learning enables rapid identification of potent DDR1 kinase inhibitors. Nat. Biotechnol. 37, 1038-103+. doi: 10.1038/ s41587-019-0224-x

\section{Conflict of Interest: SY is the cofounder of AlphaMol Science Ltd.}

The remaining authors declare that the research was conducted in the absence of any commercial or financial relationships that could be construed as a potential conflict of interest.

Copyright $\odot 2020$ Cui, Aouidate, Wang, Yu, Li and Yuan. This is an open-access article distributed under the terms of the Creative Commons Attribution License (CC BY). The use, distribution or reproduction in other forums is permitted, provided the original author(s) and the copyright owner(s) are credited and that the original publication in this journal is cited, in accordance with accepted academic practice. No use, distribution or reproduction is permitted which does not comply with these terms. 